\title{
Precursor B-cell Lymphoblastic Lymphoma of Bone in Children: A Close Mimicker of Ewing's Sarcoma
}

\begin{abstract}
Precursor B-cell lymphoblastic lymphoma (LBL) occurring as a primary bone tumor is a rare clinical presentation in children, and data regarding this condition are limited to small case series or a few individual case reports. We report two pediatric cases of precursor B-cell LBL of the bone. The tumor cells from bone biopsies of both patients were seen to be positive for leukocyte common antigen (LCA), terminal deoxynucleotidyl transferase, CD10, CD20 and weakly positive for CD99. Bone marrow studies were normal. They were treated according to the modified Berlin-Frankfurt-Münster acute lymphoblastic leukemia high-risk protocol. The first patient has completed treatment including local radiotherapy and has been disease free for the past 10 years. The second patient has recently completed treatment and shows good response.
\end{abstract}

Keywords: Bone tumors, lymphoblastic lymphoma, pediatric oncology, primary bone lymphoma

\section{Introduction}

Primary bone lymphoma $(\mathrm{PBL})$ is a rare clinical entity accounting for $<1 \%$ of all malignant lymphomas and $7 \%$ of all malignant bone tumors. ${ }^{[1]}$ According to the WHO, PBL is defined as a tumor composed of malignant lymphoid cells, producing one or more masses within bone, without any supraregional lymph node involvement or other extranodal lesions. ${ }^{[2]}$ B-cell lymphoblastic lymphoma (LBL) with primary bone involvement is infrequently reported in literature, and data regarding this condition are limited. ${ }^{[3,4]}$ We report two children with this condition.

\section{Case Report}

Case 1

A 2-year-old girl presented in 2014 with pain of the right thigh of 3-week duration. Local examination revealed tenderness of the distal end of the femur without any swelling or lymphadenopathy. Systemic examination was normal. Her hemogram was normal and lactate dehydrogenase (LDH) level was $569 \mathrm{U} / \mathrm{L}$. Radiographs showed an irregular lytic lesion involving the distal metadiaphyseal region of the right femur [Figure 1]. Magnetic resonance imaging (MRI) revealed a marrow infiltrative expansile lesion with

This is an open access journal, and articles are distributed under the terms of the Creative Commons Attribution-Non Commercial-ShareAlike 4.0 License, which allows others to remix, tweak, and build upon the work non-commercially, as long as appropriate credit is given and the new creations are licensed under the identical terms.

For reprints contact: reprints@medknow.com cortical erosion and thinning [Figure 2]. Bone scan showed abnormally increased localization at the primary site.

Bone biopsy revealed sheets of small round cells which were positive for leukocyte common antigen (LCA), terminal deoxynucleotidyl transferase (TdT), CD10, CD20 and weakly positive for CD99 [Figure 3]. Chromogranin, synaptophysin, CD3, CD5 and MPO were negative. The patient was diagnosed to have precursor B-cell LBL of the femur. Bone marrow and cerebrospinal fluid (CSF) studies were normal. She has completed chemotherapy according to the modified Berlin-Frankfurt-Münster acute lymphoblastic leukemia (ALL) protocol. She shows good response and remains free of any recurrence.

\section{Case 2}

A 7-year-old girl presented in 2006 with a 2-month history of pain of the right leg after trivial trauma. The physical examination, hemogram and LDH levels were normal. An ill-defined lytic lesion was seen on $\mathrm{X}$-ray in the proximal diaphyseal region of the right tibia, extending into the epiphysis with minimal periosteal and soft-tissue reaction. There was cortical thinning and haziness of the endosteum suggestive of a malignant lesion. She was referred to us as a case of Ewing's sarcoma.

\footnotetext{
How to cite this article: Seetharam $S$, Thankamony P, Jacob PM, Nair RA. Precursor B-cell lymphoblastic lymphoma of bone in children: A close mimicker of Ewing's sarcoma. Indian J Med Paediatr Oncol 2018;39:385-7.
}

\section{Shwetha \\ Seetharam, Priyakumari Thankamony, Priya Mary Jacob ${ }^{1}$, Rekha Appukuttan Nair ${ }^{1}$}

Division of Pediatric Oncology, Regional Cancer Centre, ${ }^{1}$ Department of Pathology, Regional Cancer Centre, Thiruvananthapuram, Kerala, India

Address for correspondence: Dr. Priyakumari Thankamony, Division of Pediatric Oncology, Regional Cancer Centre, Thiruvananthapuram - 695 011, Kerala, India.

E-mail:drpriyarcc@gmail.com

Access this article online

Website: www.ijmpo.org

DOI: 10.4103/ijmpo.ijmpo_149_16 Quick Response Code:

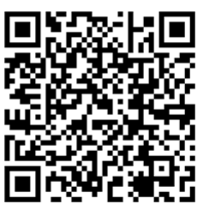




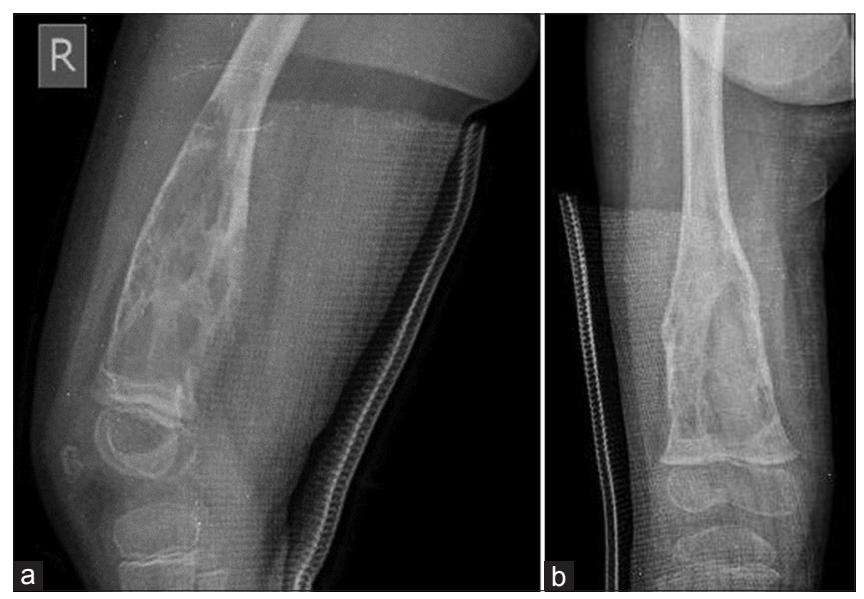

Figure 1: X-ray shows an irregular lytic lesion involving the distal metadiaphyseal region of the right femur (a) lateral view (b) anteroposterior view

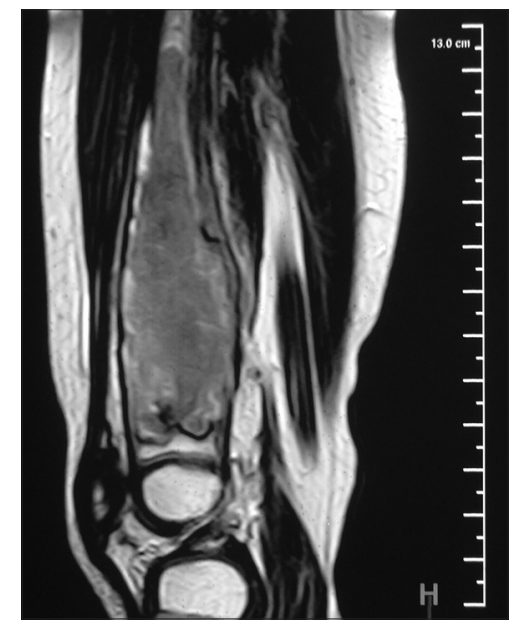

Figure 2: Magnetic resonance imaging of the right femur shows a marrow infiltrative expansile lesion in the distal metadiaphysis with cortical erosion and thinning

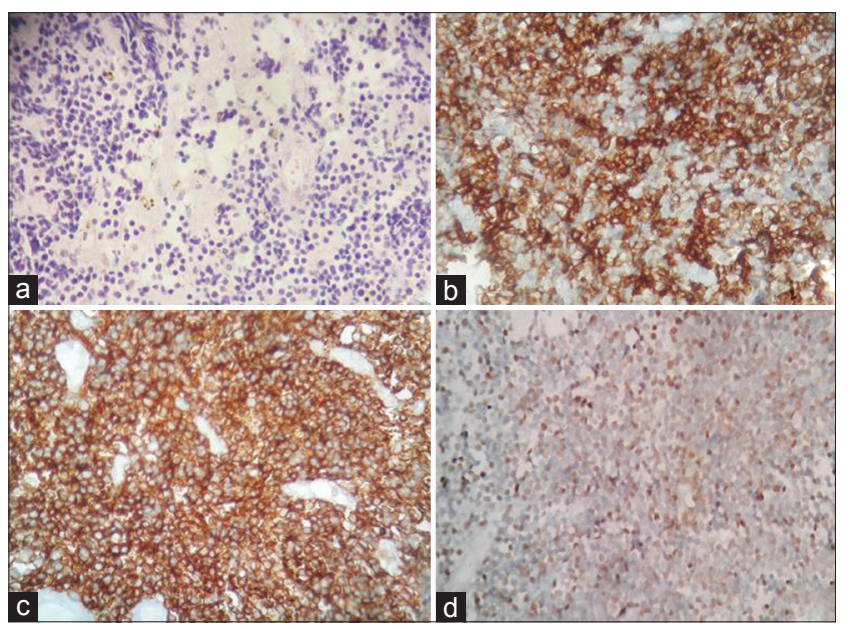

Figure 3: Histopathology. (a) Section shows tumor cells in diffuse sheets. Tumor cells have scanty cytoplasm, round nucleus, immature chromatin (H and E, $\times 100),($ b) CD10 positive (IHC, $\times 200),(c)$ CD20 positive (IHC, $\times 200)$, (d) Terminal deoxynucleotidyl transferase positive (IHC, $\times 200)$

A bone biopsy showed small cleaved lymphoid cells with immature chromatin. The tumor cells were positive for LCA, TdT, CD20, CD10 and CD99 and negative for CD3 and CD5. CSF and bone marrow biopsy were normal. She was diagnosed with precursor B-cell LBL of the bone and treated with chemotherapy according to the institutional ALL protocol for $2 \frac{1}{2}$ years along with local radiotherapy (35 Gy in 20 fractions). She remains disease free for the past 10 years.

\section{Discussion}

PBL is a rare entity of which $70 \%$ are diffuse large B-cell lymphomas. It is infrequent for a LBL to present as a PBL. ${ }^{[4]}$

LBL occurs more often in children than in adults and occurs mostly in males. ${ }^{[5]}$ It constitutes about $20 \%$ of childhood non-Hodgkin's lymphoma (NHL) and is predominantly of the precursor T-cell type. ${ }^{[6]}$ Precursor B-cell LBL is a rare entity and accounts for only 3\% of pediatric NHL. ${ }^{[7]}$ Patients with B-cell LBL often have limited stage disease which may involve isolated node or rarely skin or bone. Patients with bone involvement may present with complaints of pain and/or a palpable swelling.

PBL typically presents as a solitary, permeative, metadiaphyseal lesion in a long bone with layered periosteal reaction and minimal cortical destruction. The femur is most commonly involved. ${ }^{[2,4]}$ Radiologically, the tumor may resemble osteosarcoma, Ewing's sarcoma, neuroblastoma metastasis or Langerhans cell histiocytosis. MRI is very helpful in evaluating the bone marrow involvement, associated soft-tissue masses and early detection of cortical erosion.

Precursor B-cell LBL may mimic Ewing's sarcoma (ES) which is the second most common primary bone malignancy in pediatrics and the most common round cell tumor involving the bone. ${ }^{[4]}$ It is of vital importance to distinguish B-cell LBL from ES as the clinical behavior, treatment and outcome differ significantly. The tumor cells in both conditions are uniform and small and have a diffuse and infiltrative growth pattern. Other differential diagnoses include small round cell tumors such as neuroblastoma metastasizing to bone, small cell osteogenic sarcoma, desmoplastic small round cell tumor and myeloid sarcoma.

Immunohistochemically, only two-thirds of LBLs express LCA while CD99 expression, which was believed to be specific for ES, is seen in up to $75 \%$ patients with LBL. ${ }^{[8]}$ Therefore, the probability of misdiagnosing an LCA-negative, CD99-positive tumor as ES is considerable when a limited immunohistochemical (IHC) panel is used. TdT has been found to be the best discriminator of LBL and ES [Table 1]. In addition, ES has characteristic cytogenetic and molecular genetic findings (most commonly $t(11 ; 22)$ with EWS/FLI-1 fusion) which are helpful in confirming the diagnosis. Due to technical limitations and financial constraints, molecular confirmation was not done in both of our patients. However, the diagnosis could be confirmed with the extended IHC panel. 


\begin{tabular}{lll}
\hline \multicolumn{2}{c}{ Table 1: Differences in the immunophenotypic profile of lymphoblastic lymphoma and Ewing's sarcoma } \\
\hline Ancillary test & LBL & ES \\
\hline Immunohistochemistry & Positive in 92\% cases & Negative \\
TdT & Usually positive $(62 \%)$ & Negative \\
LCA (CD45) & Positive in 75\% cases (weak membrane positivity) & Cytoplasmic and membrane pattern of positivity \\
CD99 & & \\
Molecular characteristics & Negative & Positive in $85 \%$ cases \\
EWS-FL1 fusion transcript & Negative \\
PCR for Ig heavy chain rearrangement & Positive in 90\% cases & \\
\hline TdT - Terminal deoxynucleotidyl transferase; LCA - Leukocyte common antigen; CD - Cluster differentiation; PCR - Polymerase chain \\
reaction; ES - Ewing's sarcoma; LBL - Lymphoblastic lymphoma
\end{tabular}

The current standard treatment for LBL is based on the multidrug chemotherapy protocols for leukemia. ${ }^{[9]}$ Radiotherapy also played a significant role in treatment regimens in the past, both as a single modality and in combination with chemotherapy. However, radiation is associated with an increased risk of secondary malignancies in the radiation field as reported in patients with PBL who later developed sarcomas. ${ }^{[10]}$ As various studies have shown favorable survival rates without radiation, this modality is no longer included in standard treatment plans. ${ }^{[9]}$ Our patient treated in 2014 did not receive any form of local therapy and has shown good response with chemotherapy alone while the child treated in 2006 received local radiotherapy along with systemic chemotherapy. Both patients remain free of any recurrence.

To conclude, precursor B-cell LBL of the bone is a rare occurrence which presents in children as bone pain with an associated lytic bone lesion. It can mimic ES both clinically and immunohistochemically. These children have excellent outcome when treated with multidrug chemotherapy regimens as used in leukemia. Adjunctive radiation is no longer considered necessary in the definitive treatment. Though rare, this condition may be considered in the differential diagnosis when dealing with small round cell tumors of the bone in children.

\section{Declaration of patient consent}

The authors certify that they have obtained all appropriate patient consent forms. In the form the patient(s) has/have given his/her/their consent for his/her/their images and other clinical information to be reported in the journal. The patients understand that their names and initials will not be published and due efforts will be made to conceal their identity, but anonymity cannot be guaranteed.

\section{Financial support and sponsorship}

Nil.

\section{Conflicts of interest}

There are no conflicts of interest.

\section{References}

1. Ramadan KM, Shenkier T, Sehn LH, Gascoyne RD, Connors JM. A clinicopathological retrospective study of 131 patients with primary bone lymphoma: A population-based study of successively treated cohorts from the British Columbia Cancer Agency. Ann Oncol 2007;18:129-35.

2. Hogendoorn P, Kluin PM. Primary non-Hodgkin lymphoma of bone. In: Fletcher CD, Bridge JA, Hogendoorn P, Mertens F, editors. World Health Organization Classification of Tumours: Pathology and Genetics of Tumours of Soft Tissue and Bone. $4^{\text {th }}$ ed. Lyon, France: IARC Press; 2013. p. 316-8.

3. Belgaumi AF, Al-Kofide A, Sabbah R, Shalaby L. Precursor B-cell lymphoblastic lymphoma (PBLL) in children: Pattern of presentation and outcome. J Egypt Natl Canc Inst 2005;17:15-9.

4. Ozdemirli M, Fanburg-Smith JC, Hartmann DP, Shad AT, Lage JM, Magrath IT, et al. Precursor B-lymphoblastic lymphoma presenting as a solitary bone tumor and mimicking Ewing's sarcoma: A report of four cases and review of the literature. Am J Surg Pathol 1998;22:795-804.

5. Cortelazzo S, Ponzoni M, Ferreri AJ, Hoelzer D. Lymphoblastic lymphoma. Crit Rev Oncol Hematol 2011;79:330-43.

6. Allen CE, Kamdar KY, Bollard CM, Gross TG. Malignant non Hodgkin lymphomas in children. In: Pizzo PA, Poplack DG, editors. Principles and Practice of Pediatric Oncology. $7^{\text {th }}$ ed. Philadelphia: Lippincott Williams \& Wilkins; 2016. p. 589-92.

7. Head DR, Behm FG. Acute lymphoblastic leukemia and the lymphoblastic lymphomas of childhood. Semin Diagn Pathol 1995;12:325-34.

8. Maitra A, McKenna RW, Weinberg AG, Schneider NR, Kroft SH. Precursor B-cell lymphoblastic lymphoma. A study of nine cases lacking blood and bone marrow involvement and review of the literature. Am J Clin Pathol 2001;115:868-75.

9. Termuhlen AM, Smith LM, Perkins SL, Lones M, Finlay JL, Weinstein $\mathrm{H}$, et al. Outcome of newly diagnosed children and adolescents with localized lymphoblastic lymphoma treated on children's oncology group trial A5971: A report from the Children's Oncology Group. Pediatr Blood Cancer 2012;59:1229-33.

10. Loeffler JS, Tarbell NJ, Kozakewich H, Cassady JR, Weinstein HJ. Primary lymphoma of bone in children: Analysis of treatment results with Adriamycin, Prednisone, Oncovin (APO), and local radiation therapy. J Clin Oncol 1986;4:496-501. 